\title{
Impact of the antipneumococcal conjugate vaccine on the occurrence of infectious respiratory diseases and hospitalization rates in children
}

\author{
Wanderci Marys Oliveira Abrão $0^{[1]}$, Luane Marques de Mello ${ }^{[2]}$, \\ Anderson Soares da Silva ${ }^{[2]}$ and Altacílio Aparecido Nunes ${ }^{[2]}$
}

[1]. Programa de Pós-Graduação, Faculdade de Medicina de Ribeirão Preto, Universidade de São Paulo, Ribeirão Preto, SP. [2]. Faculdade de Medicina de Ribeirão Preto, Universidade de São Paulo, Ribeirão Preto, SP.

\begin{abstract}
Introduction: In 2010, to reduce the occurrence of serious pneumococcal disease, the Ministry of Health in Brazil incorporated the 10-valent pneumococcal vaccine in the immunization schedule of children younger than two years of age. The objective of this study was to evaluate the impact of vaccination on the incidence of infectious respiratory diseases in infants before and after the introduction of the 10-valent pneumococcal vaccine. Methods: This cross-sectional study involved primary care and hospital networks from a city in Minas Gerais State, Brazil, between 2009 and 2012. Results: A 40\% reduction in the prevalence of community-acquired pneumonia (CAP) was observed after introducing the pneumococcal conjugate vaccine. Male children were $28 \%$ more likely to develop the disease. The prevalence ratio ([PR $]=1.96,95 \% \mathrm{CI}: 1.52$ to $2.53, \mathrm{p}<0.05$ ) suggested that not being vaccinated was associated with the occurrence of pneumonia. The prevalence of CAP was $70 \%$ lower (PR 0.30, 95\% CI: 0.24 to $0.37, \mathrm{p}<0.05$ ) in children vaccinated as recommended compared to children with delayed vaccination, suggesting that the updated vaccine schedule improves protection. Conclusions: Immunization with the 10 -valent pneumococcal vaccine appeared to reduce the number of pneumonia cases in children during the study period. Prospective studies are needed to confirm the efficacy of the vaccine against the occurrence of pneumococcal pneumonia.
\end{abstract}

Keywords: 10-valent pneumococcal vaccine. Respiratory infections. Infants. Brazil.

\section{INTRODUCTION}

Since the early twentieth century, research has sought to contain and prevent respiratory diseases such as pneumonia, otitis media, sinusitis, and meningitis caused by Streptococcus pneumoniae. In 2010, the 10-valent pneumococcal conjugate vaccine (10VPCV) was introduced to the Brazilian basic immunization calendar to reduce morbidity and mortality in children under five years of age; pneumococcal diseases, primarily community-acquired pneumonia (CAP), significantly impact morbidity in this age group ${ }^{(1)(2)(3)}$.

According to a report by Rodrigues ${ }^{(4)}$, Brazilian CAP-related deaths in children younger than one year of age and between one and four years of age decreased by $74 \%$ and $56 \%$, respectively, between 1991 and 2007. Of an estimated 120 million CAP episodes in children worldwide in 2011, 14 million progressed

Address to: Prof. Altacílio Aparecido Nunes. Dept ${ }^{\circ}$ de Medicina Social/FMRP/ USP. Av. Bandeirantes 3900, Campus Universitário, 14049-900 Ribeirão Preto, SP, Brasil.

Phone: 55 16 3602-2884

e-mail: altacilio@fmrp.usp.br

Received 9 January 2015

Accepted 3 March 2015 to severe disease, with 1.3 million deaths, $81 \%$ in children younger than two years of age ${ }^{(5)(6)}$. A recent publication by Black $^{(7)}$ stated that pneumonia remains the most commonly experienced complication, accounting for $18 \%$ (1.5 million) of the estimated 8.7 million deaths in children. However, the proportion of deaths attributed to CAP varies widely among regions with different health systems ${ }^{(8)}$.

Pneumococci can lead to asymptomatic infections of the respiratory tract and cause invasive diseases, such as otitis, sinusitis, meningitis, and pneumonia. Global pneumococcal resistance to antibiotics is approximately $19 \%$, according to the international criteria of the Clinical and Laboratory Standards Institute (CLSI) ${ }^{(9)}$. In Brazil, the reported resistance rate ranges from $21.2 \%$ to $55 \%$ for children $8-71$ months of age and $19 \%$ to $43 \%$ in the general population ${ }^{(10)}$, with a reported pneumococcal colonization rate of $21 \%$ and $35.8 \%$ in children in States of São Paulo and Goiás, respectively ${ }^{(11)(12)}$. Other publications have reported colonization rates of $40 \%$ in children younger than 2 years old, with highest prevalence during the first year of life ${ }^{(10)}$ (11) (13). The increased resistance of airway-colonizing pathogens due to indiscriminate antibiotic use affects the entire community and complicates treatment ${ }^{(14)}$. Of 91 identified S. pneumoniae serotypes, 10 are responsible for $60-80 \%$ of disease, depending on the geographical region. 
Prevention is the most effective method of reducing pneumococcal disease, and immunization reduces bacterial dissemination. Vaccination is one of a set of procedures offered by primary health care services because health is an unquestionable right of citizenship ${ }^{(15)}$. Due to the good seroconversion results achieved with the vaccine, the national immunization program (NIP) has implemented the 10VPCV as part of the immunization schedule for children younger than two years old.

This study quantitatively evaluated children up to 24 months of age diagnosed with infectious diseases of the upper and lower airways in a small town before and after introduction of the 10 VPCV by the NIP.

\section{METHODS}

This cross-sectional study was conducted in the primary care system of Guaranésia and in the hospitals of Guaranésia and Guaxupé, State of Minas Gerais, in southern Brazil. Data were collected from hospitalized children and from children treated as outpatients for respiratory diseases.

For hospitalized children, a survey of the charts of children 0-24 months of age was conducted from 2009 to 2012 in Santa Casa, Guaranésia, and Santa Casa, Guaxupé; the target population was all children in this age group who lived in the city during that time period. For children who were treated on an outpatient basis, the data and procedures performed during primary care visits were collected only in the municipality of Guaranésia. A survey was conducted of consultations between 2009-2012, with filters for patient age, attending physician, ambulatory care unit, and family health care unit. A records search was then conducted to identify pneumonia, acute otitis media, and sinusitis clinical diagnoses. Data recorded using the International Classification of Diseases (ICD) diagnosis codes of A40.3, J13, J15.8, J15.9, J18.9, or J18.0 were analyzed; all other admissions were discarded. Patient name, age, sex, diagnosis, address, and affiliation were collected from these records.

Records of children 0-24 months of age with comorbidities related to cardiac diseases, central nervous system diseases, birth defects, gastroesophageal reflux, or aspiration pneumonia were excluded. Using diagnostic confirmation and patient information, each child's vaccine status was checked at the time of admission and after consulting the records stored in consultation room files.

\section{Statistical analysis}

To analyze the association between variables, an association estimator, the prevalence ratio (PR), was used with a $95 \%$ confidence interval. To evaluate the differences between central tendency measurements, Student's t test was used for independent samples (averages), and the Wilcoxon test was used for medians. In the analysis of difference between proportions, the chi-squared test was used. All calculations used a 5\% significance level. A sample size calculation was not necessary because we included all vaccinated individuals in the reported period.

\section{Ethical considerations}

The research project was submitted to the Ethics Committee of the University Research Center at the Educational Guaxupé Foundation [Universidade da Fundação Educacional Guaxupe (UNIFEG)] and approved at its $54^{\text {th }}$ regular meeting held on September 18, 2012 under Protocol 258.

\section{RESULTS}

This study compared the hospitalization rates and outpatient diagnoses of CAP, acute otitis media (AOM), and sinusitis in children in a city within Minas Gerais (MG) in 2009-2012. The comparison evaluated differences in cases before and after introduction of the 10VPCV to the NPI calendar recommended by the Ministry of Health. A total of 377 records (198 boys and 179 girls) were evaluated, including hospitalized children or children treated on an outpatient basis for one of three respiratory diseases. The general characteristics of the children included in this study are presented in Table 1.

The median ages of boys and girls were 12 and 13 months, respectively. Among children diagnosed with CAP, the median age was nine months, which was significantly younger than those children who did not have CAP (14 months, $\mathrm{p}<0.05$ ). The median age of children diagnosed with otitis media was 13 months, compared to a median age of 11.5 months for those who did not present with the disease $(\mathrm{p}<0.05)$. Children with sinusitis had a median age of 18.5 months, compared to 11 months for those without sinusitis $(\mathrm{p}<0.05)$.

There was a statistically significant reduction in CAP cases $(\mathrm{PR}=0.60 ; 95 \% \mathrm{CI}: 0.46$ to $0.78 ; \mathrm{p}<0.05)$ after introduction of the 10VPCV (2011-2012), as shown in Table 2.

We observed a greater incidence of CAP among boys (Table 3) when comparing disease occurrence before (2009-2010) and after (2011-2012) introduction of the 10VPCV. Before introduction of the vaccine, boys displayed a $28 \%$ higher CAP prevalence than girls ( $\mathrm{PR}=1.28 ; 95 \% \mathrm{CI}$ : 1.02 to $1.60 ; \mathrm{p}<0.05)$.

An analysis of AOM cases after vaccine introduction revealed a decrease in the number of cases of the disease in 2011; however, there was a marked increase in cases in 2012. Our data indicate an increase in otitis media cases after the introduction of the 10VPCV (Table 4) and an association between vaccination and disease occurrence. The percentage of female children diagnosed with otitis media was higher than that of males in 2009 and 2010. After introducing immunobiological data, we observed an equal trend in otitis media susceptibility, indicating no gender-based prevalence.

A high number of outpatient sinusitis cases were observed in 2009 and 2010 among children 12-24 months of age. After introduction of the vaccine in 2011, we observed a decrease in the number of outpatient cases. However, in 2012, the 12-24 month age group had the highest number of cases compared to other age groups. There was no gender difference in the prevalence of sinusitis either before (2009-2010) or after (2011-2012) the vaccine was introduced $(\mathrm{PR}=0.96 ; 95 \%$ CI: 0.60 to $1.55 ; \mathrm{p}>0.05$ ). Children's attendance data at 
TABLE 1 - General characteristics and comparison of children selected for the study from 2009 to 2012 , considering the general population studied and those with a diagnosis of communityacquired pneumonia, acute otitis media and sinusitis.

\begin{tabular}{|c|c|c|}
\hline & \multicolumn{2}{|c|}{ Community-acquired pneumonia } \\
\hline & yes & no \\
\hline Number & 174 & 203 \\
\hline Lower age (month) & 1.00 & 1.00 \\
\hline Maximum age (month) & 24.00 & 23.00 \\
\hline Median & 9.00 & 14.00 \\
\hline \multirow[t]{4}{*}{$95 \% \mathrm{CI}$} & $7.00-10.00$ & $13.00-15.00$ \\
\hline & \multicolumn{2}{|c|}{$\mathrm{p}<0.05$} \\
\hline & \multicolumn{2}{|c|}{ Acute otitis media } \\
\hline & yes & no \\
\hline Number & 147 & 230 \\
\hline Lower age (month) & 1.00 & 1.00 \\
\hline Maximum age (month) & 23.00 & 24.00 \\
\hline Median & 13.00 & 11.50 \\
\hline \multirow[t]{4}{*}{$95 \% \mathrm{CI}$} & $12.00-14.00$ & $10,00-13.00$ \\
\hline & \multicolumn{2}{|c|}{$\mathrm{p}<0.05$} \\
\hline & \multicolumn{2}{|c|}{ Sinusitis } \\
\hline & yes & no \\
\hline Number & 58 & 319 \\
\hline Lower age (month) & 9.00 & 1.00 \\
\hline Maximum age (month) & 23.00 & 24.00 \\
\hline Median & 18.50 & 11.00 \\
\hline \multirow[t]{2}{*}{$95 \% \mathrm{CI}$} & $17.00-19.00$ & $10.00-12.00$ \\
\hline & \multicolumn{2}{|c|}{$\mathrm{p}<0.05$} \\
\hline
\end{tabular}

95\% CI: 95\% confidence interval.

six months of age, when a third dose of $10 \mathrm{VPCV}$ is typically administered, revealed a sharp drop in the prevalences of the three respiratory diseases analyzed in this study. The number of affected children older than 12 months of age decreased in 2011, but AOM indices and sinusitis cases increased in 2012.

Table 5 shows a comparison of children who received the vaccination as recommended and children with delayed vaccinations revealed a prevalence of CAP among children with correctly timed vaccination $(\mathrm{PR}=0.30 ; 95 \% \mathrm{CI}$ : 0.24 to $0.37 ; \mathrm{p}<0.05)$.

However, the comparison of the incidence of otitis media between non-vaccinated and vaccinated individuals yielded a PR of 0.47 (95\% CI: 0.35 to $0.64 ; \mathrm{p}<0.05)$.

No association between vaccination and the occurrence of sinusitis was observed ( $P R=1.05 ; 95 \%$ CI: 0.65 to $1.70 ; p>0.05$ ).
TABLE 2 - Analysis on the association between vaccination and the occurrence of community-acquired pneumonia comparing the years 2009-2010 and 2011-2012, Guaranésia, State of Minas Gerais, Brazil.

\begin{tabular}{lccc}
\hline & \multicolumn{3}{c}{ Community-acquired pneumonia } \\
\cline { 2 - 4 } Period & yes & no & total \\
\hline $2011-2012$ & 49 & 99 & $148(53.7 \%)$ \\
$2009-2010$ & 125 & 103 & $228(46.3 \%)$ \\
Total & 174 & 202 & $376(100.0 \%)$ \\
PR (2011-2012 vs 2009-2010) & & 0.60 & \\
$95 \%$ CI & & $0.46-0.78$ & \\
& & $\mathrm{p}<0.05$ & \\
\hline
\end{tabular}

PR: prevalence ratio; 95\% CI: 95\% confidence interval.

TABLE 3 - Analysis on the association between vaccination and the occurrence of community-acquired pneumonia with regard to gender, Guaranésia, State of Minas Gerais, Brazil.

\begin{tabular}{lccc}
\hline Community-acquired pneumonia & Male & Female & Total \\
\hline Yes & 96 & 107 & $203(53.8 \%)$ \\
No & 102 & 72 & $174(46.2 \%)$ \\
\hline Total & 198 & 179 & 377 \\
\hline PR (2009-2010 vs 2011-2012) & & 1.28 \\
$95 \%$ CI & \multicolumn{3}{c}{$1.02-1.60$} \\
& & $\mathrm{p}<0.05$ \\
\hline
\end{tabular}

PR: prevalence ratio; $\mathbf{9 5 \%}$ CI: 95\% confidence interval.

\section{DISCUSSION}

Brook and Gober ${ }^{(16)}$ observed a reduction in oropharynx and nasal colonization by S. pneumoniae in children after the introduction of pneumococcal conjugate vaccines, with a relative increase in the presence of nontypeable Haemophilus influenza; the reported cases of sinusitis may have been caused by these pathogens. A surveillance study conducted by Pelton et al. ${ }^{(17)}$ from 2000-2003 in two Massachusetts communities revealed that colonization by vaccine serotypes decreased from $22 \%$ to $2 \%$. Meanwhile, the prevalence of several vaccine serotypes increased from $7 \%$ to $16 \%$. Veenhoven et al. ${ }^{(18)}$ noted that there was no reduction in the number of otitis media episodes in a group of individuals who received the pneumococcal conjugate vaccine and that, while vaccine serotypes were reduced in the nasopharynx after vaccination, there was immediate and complete replacement by non-vaccine serotypes. Félix ${ }^{(19)}$ reported that the heptavalent pneumococcal vaccine did not cause a significant reduction in the overall incidence of otitis media and described microbiological profile changes. These 
TABLE 4 - Analysis on the association between vaccination and the occurrence of acute otitis media in relation to gender, Guaranésia, State of Minas Gerais, Brazil.

\begin{tabular}{lccc}
\hline Acute otitis media & Male & Female & Total \\
\hline Yes & 130 & 100 & $230(61.0 \%)$ \\
No & 68 & 79 & $147(39.0 \%)$ \\
\hline Total & 198 & 179 & $377(100.0 \%)$ \\
\hline PR (2009-2010 vs 2011-2012) & & 0.77 \\
$95 \%$ CI & $0.60-1.00$ \\
& & $\mathrm{p}>0.05$ \\
\hline
\end{tabular}

PR: prevalence ratio; 95\% CI: 95\%confidence interval.

TABLE 5 - Distribution of cases of Community-acquired pneumonia in children aged $0-24$ months in relation to vaccination status (unvaccinated, vaccinated/updated, vaccinated/delayed) in the municipality of Guaranésia, State of Minas Gerais, Brazil.

\begin{tabular}{lccc}
\hline & No & Yes & Total \\
\hline Vaccination status & 62 & 86 & $148(39.4 \%)$ \\
unvaccinated & 140 & 59 & $199(52.9 \%)$ \\
vaccinated/updated & 0 & 29 & $29(7.7 \%)$ \\
vaccinated/delayed & 202 & 174 & 376 \\
\hline Total & $(53.7 \%)$ & $(46.3 \%)$ & $(100.0 \%)$ \\
\hline
\end{tabular}

findings confirm those of Block $^{(20)}$, who reported an increased incidence of otitis media caused by $H$. influenzae and Moraxella catarrhalis during the post-vaccine period accompanied by reduced pneumococcal disease. A study conducted in Norway reported that after introducing the 7-valent pneumococcal conjugate vaccine (7VPCV), the prevalence of nasopharyngeal colonization in children remained unchanged after widespread vaccination $(77.7 \%$ versus $80.2 \%)$. This finding may explain the steady incidence levels of sinusitis among vaccinated individuals in this study. The decrease in 7VPCV serotypes among carriers was completely compensated by an increase in non-7VPCV serotypes, similar to reports in other locations ${ }^{21}$.

The evaluation of hospitalization records and outpatient care visits during the 10VPCV post-introduction period revealed a $40 \%$ reduction in CAP prevalence, a significant decrease (PR: $0.60 ; 95 \%$ CI: 0.46 to $0.78 ; \mathrm{p}<0.05$ ) that suggests the effectiveness of 10VPCV in reducing CAP prevalence in the period after introduction of the vaccine (2011-2012). According to Tsai ${ }^{(22)}$, after introducing the vaccine, the US hospitalization rate for pneumonia decreased by $66 \%$ among children younger than two years of age, while in Brazil, there was a $31 \%$ decrease in the number of pneumonia cases with viral isolation ${ }^{(23)(24)}$.
Seasonal incidence changes were detected in this study, with increased hospitalizations occurring between April and June. While the number of occurrences dropped after introducing the 10VPCV, hospitalization rates remained higher in this period compared to other times of the year. There were no major differences in the seasonal trend between the vaccinated and unvaccinated time periods. Seasonal variation is a relevant factor that may lead to serious consequences and a higher number of deaths, particularly in developing countries ${ }^{(25)(26)}$. In 2013, Tamayo and Bastard ${ }^{(27)}$ reported a slight predominance of respiratory diseases in children during the winter months, a finding that aligns with the data in this study.

Our data also indicate an increased number of otitis media cases after introduction of the 10VPCV, an observation that was also reported by Block et al. ${ }^{(20)}$. This finding can be explained by replacement by $H$. influenzae and $M$. catarrhalis during the post-vaccine period, accompanied by a reduction in pneumococcal otitis media. The higher prevalence in other studies $^{(28)(29)}$ in children between six and 24 months of age conflicts with the findings of this study. In 2009 and 2010, there was outpatient care for children with otitis media in all age groups, predominantly among those 12-24 months of age. After introducing the vaccine in 2011 , there was a decrease ${ }^{(30)}$ in care required for children younger than six months of age; however, the prevalence remained highest among children between 12 and 24 months of age and increased in other strata compared to previous years. Felix ${ }^{(19)}$ reported that the 7VPCV did not cause a significant reduction in the overall incidence of otitis media but that the microbiological profile of this disease changed.

Statistical analysis suggested that non-vaccination is a risk factor for $\mathrm{CAP}(\mathrm{PR}=1.96$; $95 \% \mathrm{CI}$ : 1.52 to 2.53 ; $\mathrm{p}<0.05$ ). A comparison of CAP prevalence in children vaccinated as recommended and children with delayed vaccinations revealed a PR of 0.30 (95\% CI: 0.24 to $0.37 ; \mathrm{p}<0.05)$ among children with correctly timed vaccinations, indicating that updated vaccinations may be a protective factor against disease occurrence. Similar comparisons of AOM among unvaccinated and vaccinated children confirmed that the pneumococcal vaccine protects against $\mathrm{AOM}$ ( $\mathrm{PR}=0.47,95 \% \mathrm{CI}: 0.35$ to 0.64 ; $\mathrm{p}<0.05$ ). Finally, an analysis of sinusitis prevalence revealed no association between vaccination status and disease occurrence $(\mathrm{PR}=1.05,95 \%$ CI: 0.65 to $1.70 ; \mathrm{p}>0.05)$.

This study observed a significant reduction in CAP occurrence rates in children younger than two years old (infants) after the 10VPCV was introduced to the NIP immunization schedule. However, no reduction in the prevalence of otitis media and sinusitis was observed, suggesting that most cases (particularly for otitis media) are caused by other pathogens, particularly viruses, as well as other strains that are not found in the vaccine.

Despite these results, this study had several limitations. In this cross-sectional study, temporality, one of the main criteria of causality, is not guaranteed. However, the findings are in accordance with the literature, thus minimizing this potential limitation. In addition, disease diagnosis was based on medical records from hospitals (hospitalizations) and 
outpatient records (queries), which could lead to potential bias due to errors inherent in medical practice. However, for cases of CAP, otitis media and sinusitis, the suspicion and confirmation of diagnoses are essentially clinical and occasionally require radiographic supplementation, particularly in pneumonia cases and, more rarely, in sinusitis cases. Thus, we believe that the diagnostic criteria and confirmations cannot be neglected here because the children in this study were treated by doctors experienced in pediatric care.

In conclusion, disease prevention and health promotion are a primary goal, and vaccination programs can contribute to improvements in population health standards. In this decade, vaccines implemented by immunization programs, including the pneumococcal conjugate vaccines, have been demonstrated to be safe, efficient, and effective in reducing illness and death caused by $S$. pneumoniae. In countries where vaccination has been implemented and maintained with high coverage, the reduction of invasive pneumococcal disease has been significant. Similarly, this study demonstrated a reduction in the number of children affected by CAP. However, to maximize vaccine effects, homogeneous coverage should be the goal of all primary care units.

\section{CONFLICT OF INTEREST}

The authors declare that there is no conflict of interest.

\section{REFERENCES}

1. Ministério da Saúde. Organização Pan-Americana da Saúde. Avaliação de impacto na saúde das ações de saneamento: marco conceitual e estratégia metodológica. Organização Pan-Americana da Saúde. Brasília: Ministério da Saúde; 2004.

2. World Health Organization. Pneumococcal vaccines WHO position paper - 2012 recommendations. Vaccine 2012; 30:47174718.

3. Inge A, Arne SS. Mortalidade por pneumonia entre crianças brasileiras: uma história de sucesso. J Pediatr 2011; 8:85-87.

4. Rodrigues FE, Tatto RB, Vauchinski L, Leães LM, Rodrigues $\mathrm{MM}$, Rodrigues VB, et al. Mortalidade por pneumonia em crianças brasileiras até 4 anos de idade. J Pediatr 2011; 87:111-114.

5. Walker CL, Rudan I, Liu L, Nair H, Theodoratou E, Bhutta ZA, et al. Global burden of childhood pneumonia and diarrhea. Lancet 2013; 381:1405-1416.

6. Bryce J, Boschi-Pinto C, Shibuya K, Black RE, WHO Child Health Epidemiology Reference Group. WHO Estimates of the Causes of Death in Children. Lancet 2005; 365:1147-1152.

7. Black S. The volatile nature of pneumococcal serotype epidemiology: potential for misinterpretation. Pediatr Infect Dis J 2010; 29:301-303.

8. Rudan I, Boschi-Pinto C, Biloglav Z, Mulholland K, Campbell H. Epidemiology and etiology of childhood pneumonia. Bull World Health Org 2008; 86:408-416.

9. Ballalai I, Migowski E, Kfouri R, Brandileone MCC. Doença Pneumocócica Invasiva (DPI). Importância e impacto na saúde. Ano II, n. 12. Informativo da Sociedade Brasileira de Imunização; 2008; p. 1-12.
10. Cardozo DM, Nascimento-Carvalho CM, Andrade AL, SilvanyNeto AM, Daltro CH, Brandão MA, et al. Prevalence and risk factors for nasopharyngeal carriage of Streptococcus pneumoniae among adolescents. J Med Microbiol 2008; 57:185-189.

11. Lucarevschi BR, Baldacci ER, Bricks LF, Bertoli CJ, Teixeira LM, Mendes CMF, et al. Colonização da orofaringe de crianças por Streptococcus pneumoniae em crianças de creches de Taubaté (SP): correlação entre os principais sorotipos e a vacina conjugada heptavalente. J Pediatr 2003; 79:215-220.

12. Laval CB, Andrade AL, Pimenta FC, Andrade JG, Oliveira RM, Silva AS, et al. Serotypes of carriage and invasive isolates of Streptococcus pneumoniae in Brazilian children in the era of pneumococcal vaccines. Clin Microbiol Infect 2006; 12:50-55.

13. Greenberg D. The shifting dynamics of pneumococcal invasive disease after the introduction of the pneumococcal 7-valent conjugated vaccine: toward the new pneumococcal conjugated vaccines. Clin Infect Dis 2009; 49:213-215.

14. Sih TM, Bricks LF. Otimizando o diagnóstico para o tratamento adequado das principais infecções agudas em otorrinopediatria: tonsilite, sinusite e otite média. Rev Bras Otorrinolaringol 2008; 74:755-762.

15. Ministério da Saúde. Secretaria de Vigilância em Saúde. Departamento de Análise de Situação de Saúde. 2008: 20 Anos de Sistema Único de Saúde (SUS) no Brasil. Il- Série G, Estatística e Informação em Saúde. Brasília: Ministério da Saúde; 2009.

16. Brook I, Gober AE. Frequency of recovery of pathogens from the nasopharynx of children with acute maxillary sinusitis before and after the introduction of vaccination with the 7-valent pneumococcal vaccine. Int J Pediatr Otorhinolaryngol 2007; 71:575-579.

17. Pelton SI, Loughlin AM, Marchant CD. Seven Valent Pneumococcal Conjugate Vaccine Immunization in Two Boston Communities: Changes in Serotypes and Antimicrobial Susceptibility Among Streptococcus pneumoniae Isolates. Pediatr Infect Dis J 2004; 23:1015-1022.

18. Veenhoven R, Bogaert D, Uiterwaal C, Brouwer C, Kiezebrink H, Bruin J, et al. Effect of conjugate pneumococcal vaccine followed by polysaccharide pneumococcal vaccine on recurrent acute otitis media: a randomised study Lancet 2003; 361:2189-2195.

19. Felix F, Gomes GA, Cabral GAPS, Cordeiro JR, Tomita S. The role of new vaccines in the prevention of otitis media. Rev Bras Otorrinolaringol 2008; 74:613-616.

20. Block SL, Hedrick J, Harrison C. Routine use of Prevnar in a pediatric practice profoundly alters the microbiology of acute otitis media. Paper presented at: Pediatric Academic Society Annual Meeting: Seattle, WA; 2003.

21. Vestrheim DF, Hoiby EA, Aaberge IS, Caugant DA. Impact of a pneumococcal conjugate vaccination program on carriage among children in Norway. Clin Vaccine Immunol 2010; 17:325-334.

22. Tsai CJ, Griffin MR, Nuorti JP, Grijalva CG. Changing epidemiology of pneumococcal meningitis after the introduction of pneumococcal conjugate vaccine in the United States. Clin Infect Dis 2008; 46:1664-1772.

23. Madhi SA, Klugman KP. A role for Streptococcus pneumoniae in virus-associated pneumonia. Nat Med 2004; 10:811-813.

24. Shafinoori S, Ginocchio CC, Greenberg AJ, Yeoman E, Cheddie M, Rubin LG. Impact of pneumococcal conjugate vaccine and the severity of winter influenza-like illnesses on invasive pneumococcal infections in children and adults. Pediatr Infect Dis J 2005; 24:10-16.

25. Bedran RM, Andrade CR, Ibiapina CC, Fonseca MTM, Alvim CG, Bedran MBM. Pneumonias adquiridas na comunidade na infância e adolescência. Rev Med Minas Gerais 2012; 22 (supl 7):40-47. 
26. Veras TN, Sandim G, Mundim K, Petrauskas R, Cardoso G, D’Agostin J. Perfil epidemiológico de pacientes pediátricos internados com pneumonia. Sci Med (Porto Alegre) 2010; 20:277-281.

27. Tamayo R, Caridad M, Bastart O, Emma A. Morbilidad por infecciones respiratorias agudas en pacientes menores de 5 años. MEDISAN, Santiago de Cuba 2013; 17:9073-9078.

28. Cherpillod J. Acute otitis media in children. Int J Gen Med 2011; 4:421-423.
29. Marom T, Tan A, Wilkinson GS, Pierson KS, Freeman JL, Chonmaitree T. Trends in Otitis Media-related Health Care Utilization in the United States, 2001-2011. JAMA Pediatr 2014; 168:68-75.

30. Sáfadi MAP. Critérios sorológicos de proteção contra doença invasiva em crianças após vacina pneumocócica conjugada. Rev Pediatr Mod 2007; 43:251-255. 